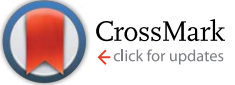

Cite this: RSC Adv., 2017, 7, 9813

Received 22nd November 2016 Accepted 26th January 2017

DOI: 10.1039/c6ra27140e

rsc.li/rsc-advances

\section{A novel total synthesis of aculeatin A via a stepwise approach $\dagger$}

\author{
Zhibin Zhang, ${ }^{a}$ Xiao Leng, ${ }^{\mathrm{b}}$ Shenkun Yang, ${ }^{a}$ Cheng Liang, ${ }^{a}$ Shuangping Huang ${ }^{\star a}$ \\ and Xiaoji Wang*c
}

Aculeatin A, isolated from the plant Amomum aculeatum, is a dispirocyclic compound having antimalarial activity. In this paper, we describe a novel synthetic approach to aculeatin A from 1-tetradecanal in nine steps via a stepwise strategy. The key features of this approach include the 1,3-diketone preparation from Claisen condensation of ketone and acyl chloride, cyclodehydration, and intramolecular oxaMichael addition to 2,3-dihydro-4H-pyran-4-one.

\section{Introduction}

Traditional medicines, which usually contain rich bioactive natural products with fascinating architectures, play a significant role in the cure of diseases such as malaria, and are therefore important sources of lead compounds. Malaria is the most important parasitic disease, causing serious effects to infected humans and killing more than 500000 every year. ${ }^{1}$ Artemisinin and chloroquine are commonly used clinically to reduce morbidity and mortality. With the widespread use of these agents, however, resistance to them has emerged in many regions. ${ }^{2}$ Therefore, identifying new and effective antimalarial agents, especially with novel mechanisms of action and neoteric chemical structures, is an important problem to be addressed by scientists. In Papua New Guinea, the plant Amomum aculeatum has long been used in folk medicine for the treatment of fever and malaria. In 2000 and 2001, Heilmann and coworkers reported four novel dispirocyclic natural products from petroleum extracts of its rhizomes, namely, aculeatins A-D (Fig. 1). ${ }^{3}$

Aculeatins A-D have attracted tremendous interest from scientists since their isolation. This new novel class of natural products exhibit interesting antimalarial activities at submicromolar level, as shown by in vitro experiments. For example, they have an $\mathrm{IC}_{50}$ of $0.18-3.0 \mu \mathrm{M}$ against Plasmodium falciparum, Trypanosoma brucei rhodesiense and Trypanosoma cruzi. Aculeatins, however, contain a novel 1,7-dioxdispiro [5.1.5.2]pentadecane skeleton, which poses a significant challenge in synthesis. Their potency as antimalarial agents and

${ }^{a}$ School of Pharmacy, Jiangxi Science and Technology Normal University, Fenglin Road 605, Nanchang 330013, China.E-mail: hsping02@gmail.com

${ }^{b}$ School of Chemistry \& Chemical Engineering, Jiangxi Science and Technology Normal University, Fenglin Road 605, Nanchang 330013, China

${ }^{c}$ School of Life Science, Jiangxi Science and Technology Normal University, Fenglin Road 605, Nanchang 330013, China.E-mail: 2012207455@tju.edu.cn

$\dagger$ Electronic supplementary information (ESI) available. See DOI: 10.1039/c6ra27140e their complex structure have thus made them popular synthetic targets in recent years. ${ }^{4}$

Over the past 15 years, more than 20 total syntheses of aculeatins have been developed using various strategies such as asymmetric allylation, ${ }^{4 c-f, q}$ kinetic resolution, ${ }^{4 l}$ and chiral pool approaches. ${ }^{4 g-j, p, m}$ In 2015 , we described a versatile approach to the syntheses of aculeatins $\mathrm{A} / \mathrm{B} / \mathrm{D} / 6-$ epi-D via an asymmetric Mukaiyama aldol reaction, ${ }^{4 t}$ ending with the protocol developed by Prof. Wong which characterized a [bis(trifluoroacetoxy)iodo] benzene (PIFA)-mediated oxidative spirocyclization (Scheme 1). However, what we obtained are the mixture of aculeatins A and B or D and 6-epi-D because of the absence of significant diaselectivity of the spirocyclization. Recently, Tong's group

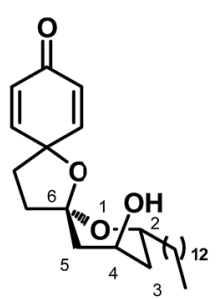

aculeatin $A$

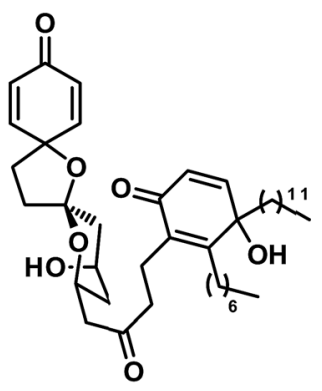

aculeatin C

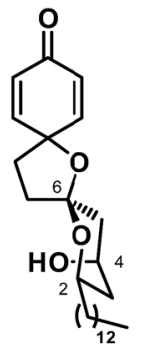

aculeatin B

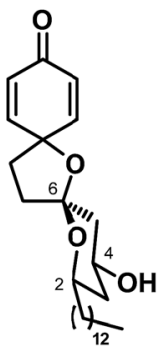

aculeatin D
Fig. 1 Structures of aculeatins A-D 
Wong's PIFA oxidative strategy

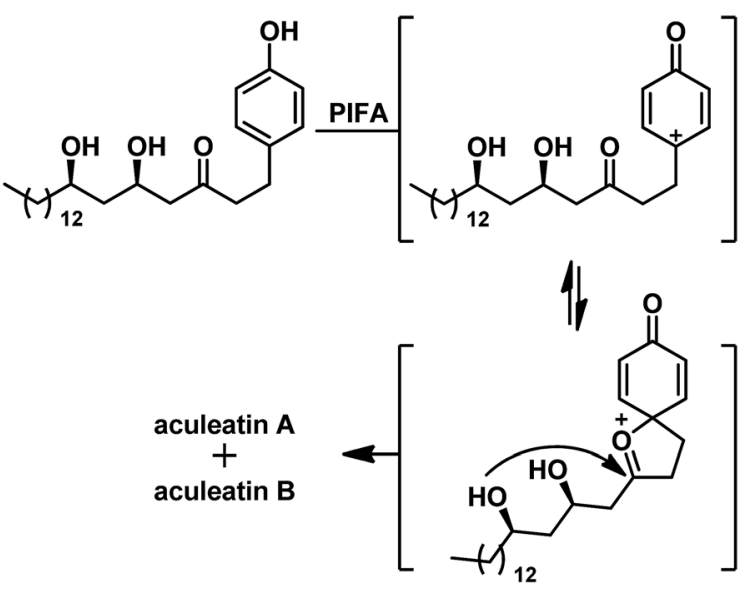

Tong's double oxa-Michael strategy
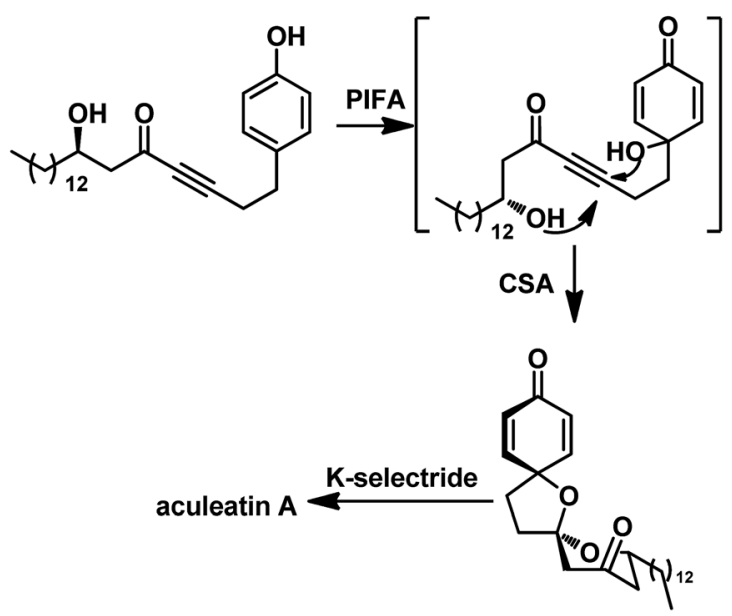

Scheme 1 Previous syntheses of aculeatin A by Wong and Tong

developed a novel double intramolecular oxa-Michael addition (DIOMA) of secondary/tertiary alcohols and subsequent selective reduction to synthesize aculeatin A, as illustrated in Scheme $1 .^{4 s}$ However, details of the sequence of DIOMA are not given in their paper, although he hypothesized in his newest review paper that 6-endo-dig double oxa-Michael addition might occur and precede a second 5-exo-trig cyclization. ${ }^{5}$ This synthesis implies that we can obtain the single spiroisomer of aculeatin if we construct the spiro structure stepwise. Herein, we report a novel and straightforward approach to the total synthesis of aculeatin A via a stepwise strategy.

Our retrosynthetic analysis is depicted in Scheme 2. Inspired by Tong's work, we envisioned that aculeatin A could be prepared by chemo- and diaselective reduction of the precursor $\mathbf{1}$. For intermediate 1, we assumed that we could carry out PIFA oxidation of the phenol and acid catalyzed intramolecular oxa-Michael addition to provide it. Therefore, we disconnected 1 from 2 . We envisioned that the hydroxyl in 2 would attack from the less hindered direction of the 2,3-dihydro- $4 \mathrm{H}$-pyran-4-one ring,
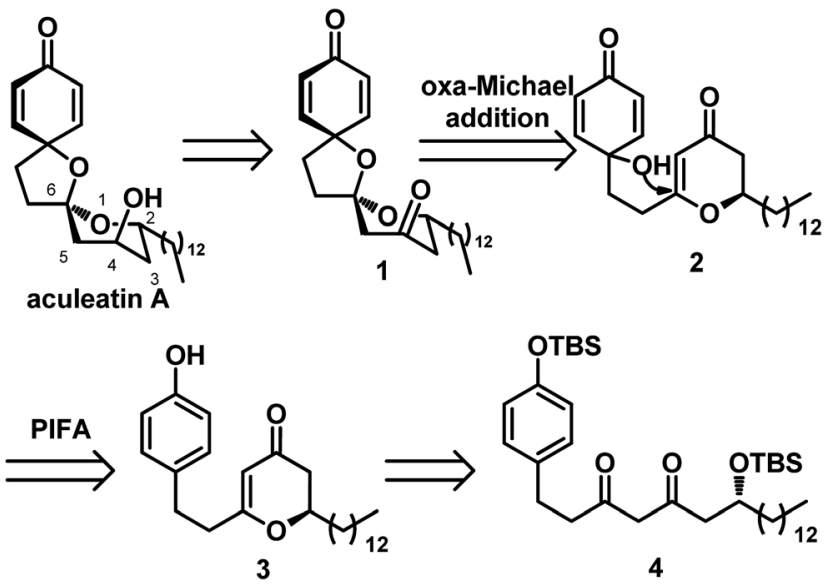

Scheme 2 Retrosynthetic analysis of aculeatin A.

resulting in the desired spiro structure during cyclization. Compound 2 could be prepared from 3 under standard conditions for PIFA oxidation. The desired 2,3-dihydro- $4 H$-pyran-4-one 3 was hypothesized to be derived from the diketone $\mathbf{4}$.

We first prepared the intermediate 4 (Scheme 3). Its route commences with the commercially available 1-tetradecanal $\mathbf{6}$. We introduced the chiral center via a Crimmins modification of the Evans aldol reaction; in the presence of $\mathrm{TiCl}_{4}$, DIPEA, and NMP, the aldol reaction between 6 and 5 thus affords the aldol adduct 7 at $65 \%$ overall yield with a diastereoselectivity of $93: 7 .^{6}$ In a preliminary study, we attempted an addition between an enolate anion with a Weinreb amide to obtain 4 .

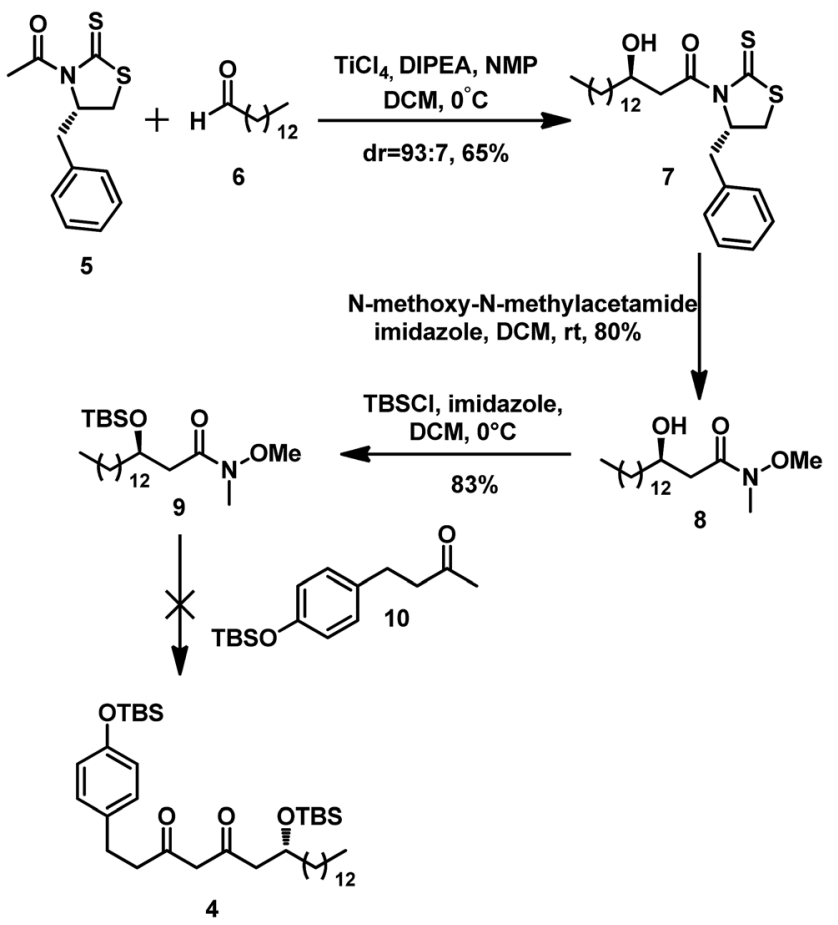

Scheme 3 Initial approach to the synthesis of the intermediate 4 via Weinreb ketone synthesis. 


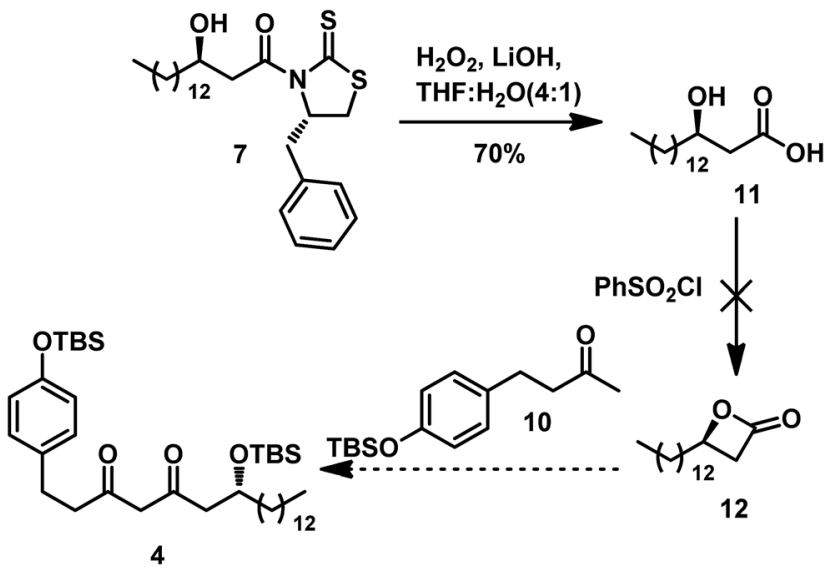

Scheme 4 Initial synthetic approach to intermediate 4 via Claisen condensation strategy.

The alcohol 7 was treated with $\mathrm{MeONHMe} \cdot \mathrm{HCl}$ to afford 8 . $^{7}$ Subsequently, the hydroxyl in $\mathbf{8}$ was protected with TBSCl in the presence of imidazole to provide Weinreb amide $\mathbf{9}$, which was then subjected to addition with ketone 10 prepared from raspberry ketone through a known procedure. ${ }^{8}$ However, we found that the enolate anion thus formed from 10 using LDA hardly reacted with 9. Harris once obtained a similar result, in which the lithium salt of acetophenone with $\mathrm{N}$-methoxy- $\mathrm{N}$-methylacetamide failed to give anything other than the starting materials. ${ }^{9}$

Thus, we adopted a Claisen condensation strategy in order to produce 4 in our retrosynthesis. We hypothesized that the condensation between the enolate anion of $\mathbf{1 0}$ with lactone $\mathbf{1 2}$ could afford 4 (Scheme 4). Therefore, removal of the auxiliary by hydrolysis with $\mathrm{LiOH}$ and $\mathrm{H}_{2} \mathrm{O}_{2}$ afforded the $\beta$-hydroxy acid 11. ${ }^{\mathbf{1 0}}$ However, we hardly obtained the desired $\beta$-lactone 12. To simplify the preparation of $\mathbf{1 2}$, we turned to the approach shown in Scheme 5; another synthetic route using acyl chloride was used to produce the intermediate 4 .

As illustrated in Scheme 5, protection of the hydroxyl group of compound 7 with TBSOTf gave TBS-ether 13 in 95\% yield.

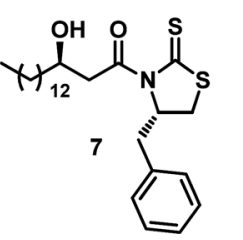

TBSOTf, 2,6-Iutidine $\mathrm{DCM}, 0^{\circ} \mathrm{C}$

$95 \%$
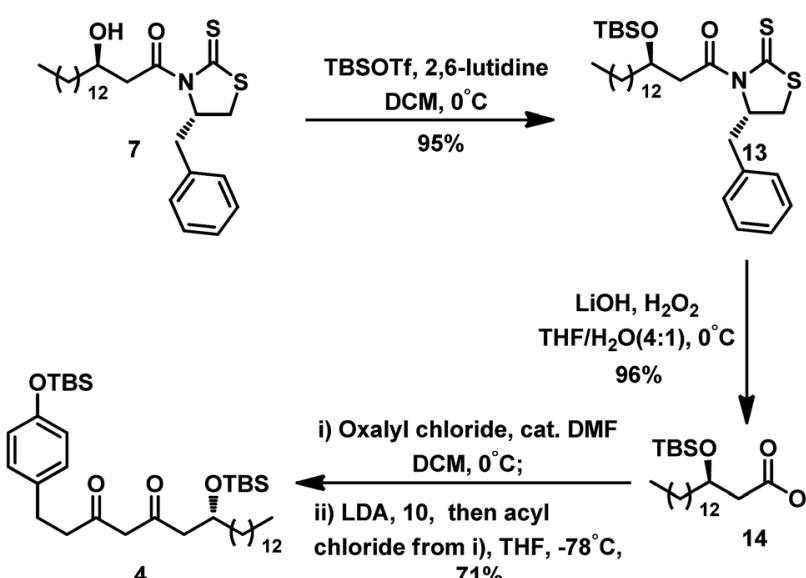

4

Scheme 5 Synthesis of intermediate 4 via acyl chloride strategy.
Similarly, removal of the auxiliary in compound 13 by hydrolysis with $\mathrm{LiOH}$ and $\mathrm{H}_{2} \mathrm{O}_{2}$ afforded acid 14. To avoid deprotection of the TBS group, mild condition was used to prepare the acyl chloride of acid 14. Treatment using the catalyst DMF at $0{ }^{\circ} \mathrm{C}$ in the presence of oxalyl chloride resulted in smooth conversion of $\mathbf{1 4}$ to its acyl chloride, ${ }^{\mathbf{1 1}}$ which was immediately subjected to Claisen condensation with the enolate anion derived from $10 .{ }^{12}$ This step generated the desired diketone intermediate 4 at $71 \%$ yield.

With diketone 4 in hand, we proceeded to construct the 2,3dihydro-4H-pyran-4-one unit (Table 1) under typical conditions ${ }^{13}$ including acid and TBAF. In the presence of TFA in DCM, the desired product was not obtained even after an extended period. One equivalent of TsOH $\cdot \mathrm{H}_{2} \mathrm{O}$ in the solvent DCM could promote the cyclization, leading to a yield of 53\%. Increasing the amount of $\mathrm{TsOH} \cdot \mathrm{H}_{2} \mathrm{O}$ to 5 equiv. resulted in a higher yield $(80 \%)$ and shorter reaction time $(10 \mathrm{~h})$. Because of the poor solubility of excess TsOH $\cdot \mathrm{H}_{2} \mathrm{O}$ in DCM, we replaced the solution with acetone. A similar yield of 3 was thus obtained in much shorter time $(5 \mathrm{~h})$. Using TBAF as the deprotection reagent, we obtained 3 at relatively low yield (62\%). We also conducted the reaction using the Lewis acid of $\mathrm{BF}_{3} \cdot \mathrm{OEt}_{2} ;{ }^{\mathbf{1 4}}$ however, it gave a very low yield (30\%) after $20 \mathrm{~h}$.

Preparation of the precursor 3 enabled us to study the construction of the spiro unit of aculeatin A. Here, PIFA is an effective oxidizing agent; it is a common reagent for the oxidation of phenol to a cyclohexadienone ring with a tertiary hydroxyl. This hydroxyl can undergo intramolecular oxaMichael addition to the 2,3-dihydro-4H-pyran-4-one unit, as described by Tong. We thus attempted the oxidation of 3 using PIFA, following the protocol of Tong. ${ }^{4 s}$ We first treated 3 with PIFA in a solvent mixture (acetone/ $\mathrm{H}_{2} \mathrm{O}$ at $9: 1$ ratio) and then removed the solvent without further purification. The product was immediately subjected to CSA because of the possible instability of intermediate 2 . Fortunately, we successfully obtained a single isomer of the desired polyspirocyclic compound 1 in 58\% yield from compound 3. The latter was easily and

Table 1 Optimization of the cyclodehydration of diketone 4

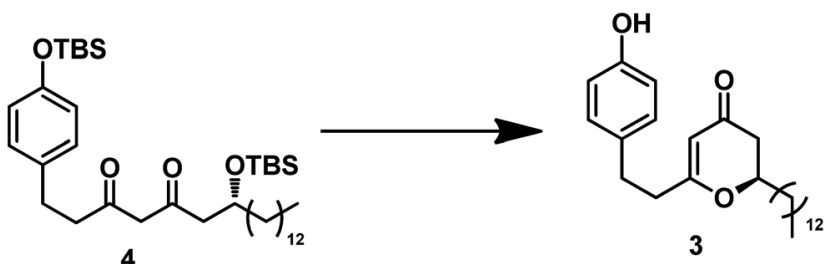

\begin{tabular}{lllll} 
Entry & Reagent (equiv.) & Solvent & Time $(\mathrm{h})$ & Yield $^{a}(\%)$ \\
\hline 1 & TFA & DCM & 50 & 0 \\
2 & TsOH $\cdot \mathrm{H}_{2} \mathrm{O}(1)$ & DCM & 24 & 53 \\
3 & $\mathrm{TsOH} \cdot \mathrm{H}_{2} \mathrm{O}(5)$ & DCM & 10 & 80 \\
4 & $\mathrm{TsOH} \cdot \mathrm{H}_{2} \mathrm{O}(5)$ & Acetone & 5 & 80 \\
5 & $\mathrm{TBAF}(4)$ & DCM & 18 & 62 \\
6 & $\mathrm{BF}_{3} \cdot \mathrm{Et}_{2} \mathrm{O}(15)$ & DCM & 20 & 30
\end{tabular}

${ }^{a}$ Yield based on isolation using silica gel. 


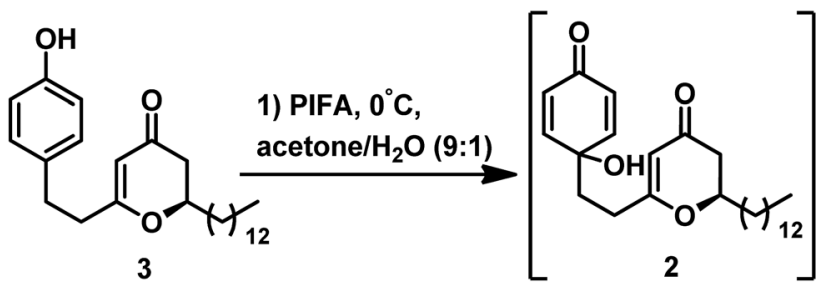

2) CSA, DCM, rt $58 \%$ from 3
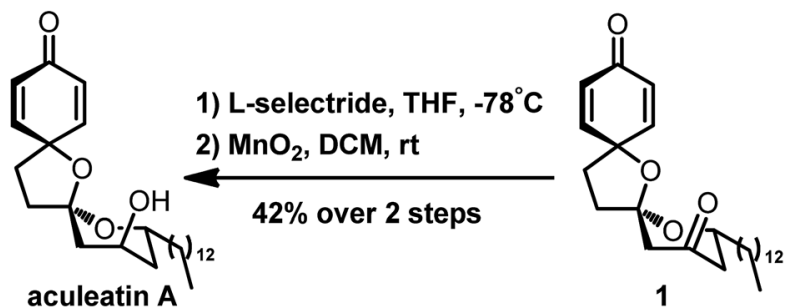

Scheme 6 Total synthesis of aculeatin A

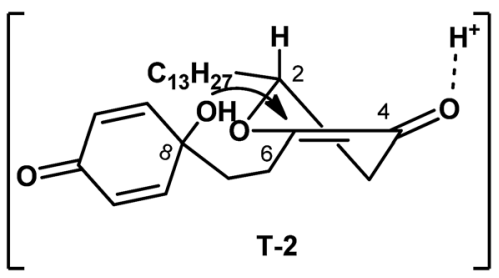

Fig. 2 Transition state in the diastereoselective oxa-Michael addition.

diaselectively reduced to aculeatin A as a single isomer through a lithium tri-sec-butylborohydride (L-selectride) $/ \mathrm{MnO}_{2}$ strategy at $42 \%$ overall yield (Scheme 6).

In our approach, preparation of aculeatin A depended critically on the highly diastereoselective intramolecular oxaMichael addition of 2. We assumed that the spirocyclization proceeded via the transition state T-2 (Fig. 2), in which the hydrogen occupied an axial position. Under the condition of acid, hydroxyl at C-8 attacked the enone from the less-hindered $R e$-face side, that is, the side of hydrogen at C-2. This step produced diastereoselectively the desired stereocenter of aculeatin A without aculeatin B. The physical properties, as well as ${ }^{1} \mathrm{H}$ and ${ }^{13} \mathrm{C}$ NMR spectra of the product are consistent with those reported in the literature. ${ }^{4 s}$

\section{Conclusions}

In summary, we have developed a novel and straightforward approach to the total synthesis of aculeatin A via a stepwise strategy, using commercially available 1-tetradecanal. This approach is the second example of a process that leads to aculeatin $\mathrm{A}$ as a single spiroisomer and is also the second example that does not end in PIFA-mediated cascade reaction involving oxidative cyclization (oxidation/spiroketalization). The total synthesis features 1,3-diketone preparation from Claisen condensation of ketone and acyl chloride, deprotection-cyclodehydration in a one-pot reaction, and intramolecular oxaMichael addition of 2,3-dihydro- $4 H$-pyran-4-one. The highly diastereoselective spirocyclization can occur during the intramolecular 5-exo-dig oxa-Michael addition in which the hydroxyl attacks from the less-hindered side. This stepwise strategy was demonstrated to be an effective protocol for constructing the spiro structure of aculeatin A, which can be useful in the syntheses of analogues of aculeatins and other natural products having a similar structure.

\section{Experimental}

\section{General}

All reactions were carried out under $\mathrm{N}_{2}$ atmosphere with dry solvents unless otherwise noted and monitored by thin-layer chromatography (TLC) carried out on $0.25 \mathrm{~mm}$ silica gel plates (60F-254). Silica gel (200-300 mesh) supplied by Qingdao Marine chemical factory in China was used for flash column chromatography. Anhydrous THF was distilled from sodiumbenzophenone. DCM $\left(\mathrm{CH}_{2} \mathrm{Cl}_{2}\right)$ and DMF were distilled from $\mathrm{CaH}_{2}$. Other solvents or reagents weren't purified. Yield refers to chromatographically and spectroscopically $\left({ }^{1} \mathrm{H},{ }^{13} \mathrm{C}\right.$ NMR), unless otherwise stated. NMR spectra were recorded on either a $400 \mathrm{MHz}$ spectrometer $\left({ }^{1} \mathrm{H}: 400 \mathrm{MHz},{ }^{13} \mathrm{C}: 100 \mathrm{MHz}\right)$ or 500 $\mathrm{MHz}\left({ }^{1} \mathrm{H}: 500 \mathrm{MHz},{ }^{13} \mathrm{C}: 125 \mathrm{MHz}\right)$. High-resolution mass spectra were obtained from a MALDI-TOF Mass Spectrometer. IR spectra were recorded on a Shimadzu FT-IR spectrophotometer. Optical rotations were measured on a digital polarimeter in $\mathrm{CHCl}_{3}$ at $25^{\circ} \mathrm{C}$.

(R)-1-((S)-4-Benzyl-2-thioxothiazolidin-3-yl)-3-((tert-butyldimethylsilyl)oxy)hexadecan-1-one (13). 2,6-Lutidine $(1.34 \mathrm{~mL}$, $11.43 \mathrm{mmol}, 2.0$ equiv. $)$ was added to the cooled $\left(0^{\circ} \mathrm{C}\right)$ solution of compound 7 ( $2.65 \mathrm{~g}, 5.70 \mathrm{mmol}, 1.0$ equiv.) dissolved in dry DCM $(57 \mathrm{~mL})$ under the protection of $\mathrm{N}_{2}$. After $10 \mathrm{~min}$, TBSOTf (1.60 $\mathrm{mL}, 6.86 \mathrm{mmol}, 1.2$ equiv.) was added to the above solution dropwise and then kept the reaction stirred at $0{ }^{\circ} \mathrm{C}$. When the TLC monitor indicated compound 7 was consumed, the reaction was quenched with sat. $\mathrm{NaHCO}_{3}$. Then the resultant mixture was extracted with DCM $(100 \mathrm{~mL} \times 3)$. The combined organic layer was washed with sat. $\mathrm{NaCl}$ solution, dried over sodium sulfate, filtered through a funnel and concentrated under reduced pressure. The residue was purified with flash chromatography (hexane/EtOAc $=20: 1$ ) to give compound 13 $(3.13 \mathrm{~g}, 95 \%) \cdot[\alpha]_{\mathrm{D}}^{25}=174.6\left(c 2.3, \mathrm{CHCl}_{3}\right) .{ }^{1} \mathrm{H}$ NMR $(500 \mathrm{MHz}$, $\left.\mathrm{CDCl}_{3}\right): \delta 7.38-7.35(\mathrm{~m}, 2 \mathrm{H}), 7.31-7.27(\mathrm{~m}, 3 \mathrm{H}), 5.30-5.26(\mathrm{~m}$, $1 \mathrm{H}), 4.38-4.33(\mathrm{~m}, 1 \mathrm{H}), 3.58$ (dd, $J=16.7,8.2 \mathrm{~Hz}, 1 \mathrm{H}), 3.35$ (dd, $J$ $=11.5,7.3 \mathrm{~Hz}, 1 \mathrm{H}), 3.27(\mathrm{dd}, J=13.2,3.8 \mathrm{~Hz}, 1 \mathrm{H}), 3.17(\mathrm{dd}, J=$ 16.7, $3.8 \mathrm{~Hz}, 1 \mathrm{H}), 3.06$ (dd, $J=13.1,10.7 \mathrm{~Hz}, 1 \mathrm{H}), 2.89$ (d, $J=$ $11.6 \mathrm{~Hz}, 1 \mathrm{H}), 1.56-1.52(\mathrm{~m}, 2 \mathrm{H}), 1.30-1.21(\mathrm{~m}, 22 \mathrm{H}), 0.90(\mathrm{t}, J=$ $6.9 \mathrm{~Hz}, 3 \mathrm{H}), 0.88(\mathrm{~s}, 9 \mathrm{H}), 0.11(\mathrm{~s}, 3 \mathrm{H}), 0.07(\mathrm{~s}, 3 \mathrm{H}) ;{ }^{13} \mathrm{C}$ NMR $(125$ $\mathrm{MHz}, \mathrm{CDCl}_{3}$ ): 201.0, 172.5, 136.6, 129.4, 128.9, 127.2, 69.3, 68.7, $45.8,37.8,36.5,32.2,31.9,29.7-29.6$ (br, 6C), 29.3, 25.8, 24.9, 22.7, 18.0, 14.1, -4.4, -4.7; IR (film): 2925, 2853, 1699, 1464, 1362, 1341, 1257, 1165, 1042, 836, 775, $701 \mathrm{~cm}^{-1}$; HRMS (ESI): $m / z$ calcd for $\mathrm{C}_{32} \mathrm{H}_{56} \mathrm{NO}_{2} \mathrm{~S}_{2} \mathrm{Si}^{+}[\mathrm{M}+\mathrm{H}]^{+}:$578.3516, found 578.3519. 
(R)-3-((tert-Butyldimethylsilyl)oxy)hexadecanoic acid (14). $\mathrm{LiOH} \cdot \mathrm{H}_{2} \mathrm{O}(0.96 \mathrm{~g}, 22.76 \mathrm{mmol}, 2.2$ equiv. $)$ and $30 \% \mathrm{H}_{2} \mathrm{O}_{2}(6.40$ $\mathrm{mL}, 62.08 \mathrm{mmol}, 6.0$ equiv.) was added to the solution of compound 13 ( $5.98 \mathrm{~g}, 10.35 \mathrm{mmol}, 1.0$ equiv.) in $\mathrm{THF} / \mathrm{H}_{2} \mathrm{O}(35$ $\mathrm{mL}, 4: 1)$ at $0{ }^{\circ} \mathrm{C}$. The mixture was then stirred at $0{ }^{\circ} \mathrm{C}$ for $1 \mathrm{~h}$. When the TLC monitor indicated compound 13 was consumed, the reaction was quenched with $\mathrm{NH}_{4} \mathrm{Cl}$ and the $\mathrm{pH}$ was adjusted to 0 using $1 \mathrm{~N} \mathrm{HCl}$. The organic layer was separated and the aqueous layer was extracted with EtOAc $(100 \mathrm{~mL} \times 3)$. The combined organic layer was then washed with sat. $\mathrm{NaCl}$ solution, dried over sodium sulfate, filtered, and concentrated in reduced pressure. The residue was purified with flash chromatography (hexane/EtOAc $=15: 1$ ) to afford the desired acid $\mathbf{1 4}$ as a white solid $(3.84 \mathrm{~g}, 96 \%) .[\alpha]_{\mathrm{D}}^{25}=0.49\left(c 2.6, \mathrm{CHCl}_{3}\right) .{ }^{1} \mathrm{H}$ NMR $\left(500 \mathrm{MHz}, \mathrm{CDCl}_{3}\right): \delta 4.14-4.11(\mathrm{~m}, 1 \mathrm{H}), 2.48(\mathrm{~d}, J=5.5 \mathrm{~Hz}, 2 \mathrm{H})$, $1.59-1.50(\mathrm{~m}, 2 \mathrm{H}), 1.30-1.21(\mathrm{~m}, 22 \mathrm{H}), 0.90(\mathrm{t}, J=6.5 \mathrm{~Hz}, 3 \mathrm{H})$, 0.88 (s, 9H), 0.08 (s, 3H), 0.07 (s, 3H); ${ }^{13} \mathrm{C}$ NMR $(125 \mathrm{MHz}$, $\mathrm{CDCl}_{3}$ ): $177.4,69.4,42.3,37.5,31.9,29.7-29.6$ (br, 5C), 29.3, 25.8, 25.0, 22.7, 18.0, 14.1, 1.0, -4.5, -4.8; IR (film): 2926, 2855, 1715, 1466, 1258, 1219, 1098, 1082, 836, $773 \mathrm{~cm}^{-1}$; HRMS (ESI): $m / z$ calcd for $\mathrm{C}_{22} \mathrm{H}_{47} \mathrm{O}_{3} \mathrm{Si}^{+}[\mathrm{M}+\mathrm{H}]^{+}:$387.3289, found 387.3281.

(R)-7-((tert-Butyldimethylsilyl)oxy)-1-(4-((tert-butyldimethylsilyl)oxy)phenyl)icosane-3,5-dione (4). Under the protection of $\mathrm{N}_{2}$, oxalyl chloride $(0.24 \mathrm{~mL}, 2.60 \mathrm{mmol}, 2.0$ equiv.) and catalytic dry DMF (0.005 mL, $0.065 \mathrm{mmol}, 0.05$ equiv.) were added sequentially to the cooled $\left(0{ }^{\circ} \mathrm{C}\right)$ solution of acid $14(0.50 \mathrm{~g}$, $1.30 \mathrm{mmol}, 1.0$ equiv. $)$ in dry DCM $(8 \mathrm{~mL})$. One hour later, the concentration of the above mixture in vacuum provided a yellow oil (crude acyl chloride), which was immediately subjected to the next step without further purification.

Under a $\mathrm{N}_{2}$ atmosphere, $n$-BuLi $(1.14 \mathrm{~mL}, 2.86 \mathrm{mmol}, 2.2$ equiv.) was added dropwise to the stirred solution of DIPA (0.40 $\mathrm{mL}, 2.86 \mathrm{mmol}, 2.2$ equiv. $)$ in anhydrous THF $(10 \mathrm{~mL})$ at $-78^{\circ} \mathrm{C}$. After stirring for $20 \mathrm{~min}$ at $-78{ }^{\circ} \mathrm{C}$, the solution of $\mathbf{1 0}(0.72 \mathrm{~g}$, $2.60 \mathrm{mmol}, 2.0$ equiv. $)$ in THF $(0.5 \mathrm{~mL})$ was added slowly to the freshly prepared LDA. The reaction was then stirred at $-78{ }^{\circ} \mathrm{C}$ for another $10 \mathrm{~min}$ followed by addition of the above acyl chloride. When the TLC monitor indicated compound $\mathbf{1 4}$ was consumed, the reaction was quenched with $1 \mathrm{~N} \mathrm{HCl}$. Subsequently, the resultant mixture was extracted with DCM $(50 \mathrm{~mL}$ $\times 3$ ) and the combined organic layer was washed with sat. $\mathrm{NaCl}$, dried over anhydrous sodium sulfate, filtered through a funnel, and concentrated under reduced pressure. Purification by flash chromatography (hexane/EtOAc $=50: 1$ ) gave the desired compound 4 as a yellow oil $(0.60 \mathrm{~g}, 71 \%)$. $[\alpha]_{\mathrm{D}}^{25}=61.6(c 0.33$, $\left.\mathrm{CHCl}_{3}\right) .{ }^{1} \mathrm{H}$ NMR $\left(500 \mathrm{MHz}, \mathrm{CDCl}_{3}\right): \delta 15.50(\mathrm{br}, 0.5 \mathrm{H}), 7.04(\mathrm{~d}, J$ $=8.0 \mathrm{~Hz}, 1.6 \mathrm{H}), 7.02-6.99(\mathrm{~m}, 0.4 \mathrm{H}), 6.78-6.77(\mathrm{~m}, 0.4 \mathrm{H}), 6.76$ $(\mathrm{d}, J=8.0 \mathrm{~Hz}, 1.6 \mathrm{H}), 5.50(\mathrm{~s}, 0.7 \mathrm{H}), 4.20-4.13(\mathrm{~m}, 0.25 \mathrm{H}), 4.11-$ $4.07(\mathrm{~m}, 0.75 \mathrm{H}), 3.74-3.53(\mathrm{~m}, 0.3 \mathrm{H}), 2.86(\mathrm{t}, J=8.0 \mathrm{~Hz}, 1.6 \mathrm{H})$, 2.82-2.77 (m, 0.4H), 2.65-2.62 (m, 0.4H), $2.56(\mathrm{t}, J=8.0 \mathrm{~Hz}$, $1.6 \mathrm{H}), 2.40-2.32(\mathrm{~m}, 1.6 \mathrm{H}), 2.23-2.08(\mathrm{~m}, 0.5 \mathrm{H}), 1.48-1.45(\mathrm{~m}$, $2 \mathrm{H}), 1.30-1.21(\mathrm{~m}, 22 \mathrm{H}), 0.99(\mathrm{~s}, 9 \mathrm{H}), 0.89(\mathrm{t}, J=6.8 \mathrm{~Hz}, 3 \mathrm{H})$, 0.87 (s, 9H), 0.19 (s, 6H), 0.08-0.03 (m, 6H); ${ }^{13} \mathrm{C}$ NMR $(125 \mathrm{MHz}$, $\left.\mathrm{CDCl}_{3}\right): 194.3,191.0,154.0,133.4,129.1,120.0,69.9,46.2,40.6$, 37.8, 31.9, 30.7, 29.7-29.5 (br, 5C), 29.3, 25.8, 25.7, 25.0, 22.7, 18.2, 18.0, 14.1, 1.0, -4.4, -4.6, -4.9; IR (film): 3471, 2958,
2927, 2856, 1612, 1511, 1472, 1258, 1023, 917, 837, $773 \mathrm{~cm}^{-1}$; HRMS (ESI): $m / z$ calcd for $\mathrm{C}_{38} \mathrm{H}_{71} \mathrm{O}_{4} \mathrm{Si}_{2}{ }^{+}[\mathrm{M}+\mathrm{H}]^{+}: 647.4885$, found 647.4894 .

(R)-6-(4-Hydroxyphenethyl)-2-tridecyl-2H-pyran-4(3H)-one (3). $p$-TsOH (53 mg, $0.31 \mathrm{mmol}, 5.0$ equiv.) was added to the stirred solution of compound 4 (40 mg, $0.062 \mathrm{mmol}, 1.0$ equiv.) in acetone $(0.5 \mathrm{~mL})$ in one portion. The reaction was kept stirred at room temperature for $5 \mathrm{~h}$. Subsequently, sat. $\mathrm{NaHCO}_{3}$ was added to quench the reaction. The resultant mixture was extracted with DCM $(10 \mathrm{~mL} \times 3)$ and the combined organic layer was washed with sat. $\mathrm{NaCl}$, dried over anhydrous sodium sulfate, filtered through a funnel, and concentrated under reduced pressure. Purification of the residence by flash chromatography (hexane/ EtOAc $=4: 1$ ) offered the desired compound 3 in yield of $80 \%$ $(20 \mathrm{mg}) \cdot[\alpha]_{\mathrm{D}}^{25}=64.0\left(c 0.53, \mathrm{CHCl}_{3}\right) .{ }^{1} \mathrm{H} \mathrm{NMR}\left(500 \mathrm{MHz}, \mathrm{CDCl}_{3}\right)$ : $\delta 7.01(\mathrm{~d}, J=8.0 \mathrm{~Hz}, 2 \mathrm{H}), 6.77(\mathrm{~d}, J=8.0 \mathrm{~Hz}, 2 \mathrm{H}), 5.31(\mathrm{~s}, 1 \mathrm{H})$, $4.32-4.30(\mathrm{~m}, 1 \mathrm{H}), 2.80(\mathrm{t}, J=7.5 \mathrm{~Hz}, 2 \mathrm{H}), 2.57-2.48(\mathrm{~m}, 2 \mathrm{H})$, 2.46-2.35 (m, 2H), 1.81-1.76 (m, 1H), 1.67-1.61 (m, 1H), 1.49$1.42(\mathrm{~m}, 1 \mathrm{H}), 1.40-1.23(\mathrm{~m}, 21 \mathrm{H}), 0.88(\mathrm{t}, J=6.7 \mathrm{~Hz}, 3 \mathrm{H}) ;{ }^{13} \mathrm{C} \mathrm{NMR}$ (125 MHz, $\left.\mathrm{CDCl}_{3}\right): 193.9,177.4,154.6,131.7,129.3,115.4,104.3$, 79.3, 40.8, 36.8, 34.4, 31.9, 31.7, 29.6-29.3 (br, 8C), 24.9, 22.6, 14.1; IR (film): 3270, 2925, 2854, 1654, 1595, 1517, 1466, 1400, 1340, 1221, 1023, 826, $773 \mathrm{~cm}^{-1}$; HRMS (ESI): $\mathrm{m} / \mathrm{z}$ calcd for $\mathrm{C}_{26} \mathrm{H}_{41} \mathrm{O}_{3}^{+}[\mathrm{M}+\mathrm{H}]^{+}:$401.3050, found 401.3052.

Ketone (1). PIFA ( $0.45 \mathrm{~g}, 1.05 \mathrm{mmol}, 1.0$ equiv.) was added to the stirred solution of compound $3(0.42 \mathrm{~g}, 1.05 \mathrm{mmol}, 1.0$ equiv.) dissolved in acetone/water $(36 \mathrm{~mL}, 9: 1)$ at $0{ }^{\circ} \mathrm{C}$. The reaction was then kept stirred in the dark for $2 \mathrm{~h}$. When the TLC monitor indicated compound 3 was consumed, anhydrous $\mathrm{Na}_{2} \mathrm{SO}_{4}$ and anhydrous $\mathrm{NaHCO}_{3}$ were added to the reaction. The mixture was then filtered and concentrated under reduced pressure. Without further purification, the residence was dissolved in DCM $(20 \mathrm{~mL})$ and CSA $(0.24 \mathrm{~g}, 1.05 \mathrm{mmol}, 1.0$ equiv.) was added to this solvent. The resultant mixture was then kept stirred overnight and quenched with sat. $\mathrm{NaHCO}_{3}$. The organic layer was separated and the aqueous layer was extracted with DCM $(20 \mathrm{~mL} \times 3)$. Subsequently, the combined organic layer was washed with sat. $\mathrm{NaCl}$, dried over sodium sulfate, filtered and concentrated in vacuum. The residence was purified by flash chromatography (hexane/EA $=3: 1$ ) to provide compound $1(0.25 \mathrm{~g}, 58 \%$ from compound 3$)$.

$[\alpha]_{\mathrm{D}}^{25}=-7.8\left(c 1.0, \mathrm{CHCl}_{3}\right) .{ }^{1} \mathrm{H}$ NMR $\left(400 \mathrm{MHz}, \mathrm{CDCl}_{3}\right): \delta 6.77$ (ddd, $J=20.8,9.6,2.8 \mathrm{~Hz}, 2 \mathrm{H}), 6.16-6.10(\mathrm{~m}, 2 \mathrm{H}), 4.17-4.11(\mathrm{~m}$, $1 \mathrm{H}), 2.77(\mathrm{~d}, J=14.4 \mathrm{~Hz}, 1 \mathrm{H}), 2.56(\mathrm{~d}, J=14.4 \mathrm{~Hz}, 1 \mathrm{H}), 2.44-2.40$ $(\mathrm{m}, 3 \mathrm{H}), 2.27-2.24(\mathrm{~m}, 1 \mathrm{H}), 2.10-2.09(\mathrm{~m}, 2 \mathrm{H}), 1.67-1.65(\mathrm{~m}$, $1 \mathrm{H}), 1.65-1.53(\mathrm{~m}, 1 \mathrm{H}), 1.30-1.22(\mathrm{~m}, 22 \mathrm{H}), 0.88(\mathrm{t}, J=6.4 \mathrm{~Hz}$, $3 \mathrm{H}) ;{ }^{13} \mathrm{C}$ NMR (125 MHz, $\mathrm{CDCl}_{3}$ ): 204.3, 185.1, 150.2, 148.4, 127.6, 127.2, 109.6, 79.7, 69.7, 49.8, 46.7, 38.7, 36.1, 34.9, 31.9, 29.6-29.3 (br, 8C), 25.4, 22.6, 14.1; IR (film): 3490, 2924, 2854, 1727, 1674, 1467, 1021, 883, 857, $773 \mathrm{~cm}^{-1}$; HRMS (ESI): $\mathrm{m} / \mathrm{z}$ calcd for $\mathrm{C}_{26} \mathrm{H}_{41} \mathrm{O}_{4}{ }^{+}[\mathrm{M}+\mathrm{H}]^{+}$: 417.3006, found 417.3000.

(-)-Aculeatin A. L-Selectride ( $0.3 \mathrm{~mL}, 0.3 \mathrm{mmol}, 2.5$ equiv.) was added dropwise to a solution of ketone $1(50 \mathrm{mg}$, $0.12 \mathrm{mmol}, 1.0$ equiv. $)$ in THF $(2.5 \mathrm{~mL})$ at $-78^{\circ} \mathrm{C}$. The reaction was kept stirred at the same temperature for $1 \mathrm{~h}$ and then quenched by addition of sat. $\mathrm{NaHCO}_{3}(2.5 \mathrm{~mL})$, EtOAc $(5 \mathrm{~mL})$, $\mathrm{H}_{2} \mathrm{O}(1.25 \mathrm{~mL})$. The organic was collected and the aqueous layer 
was extracted with EtOAc $(5 \mathrm{~mL} \times 3)$. Subsequently, the combined organic layer was washed with sat. $\mathrm{NaCl}$, dried over sodium sulfate, filtered and concentrated in vacuum. Without further purification, the residence was immediately subject to the next step. Activated $\mathrm{MnO}_{2}(0.21 \mathrm{~g}, 2.4 \mathrm{mmol}, 20$ equiv.) was added to the above crude reduction product in dry DCM (2.5 $\mathrm{mL}$ ). Five hours later, the suspension was filtered through a short pad of Celite. The solvent was removed under reduced pressure and the residence was purified by flash chromatography (hexane/EtOAc $=4: 1)$ to provide aculeatin A $(21 \mathrm{mg}, 42 \%$ from compound 1). $[\alpha]_{\mathrm{D}}^{25}=-13.5\left(c 0.2, \mathrm{CHCl}_{3}\right) .{ }^{1} \mathrm{H}$ NMR $(300$ $\left.\mathrm{MHz}, \mathrm{CDCl}_{3}\right): \delta 6.85(\mathrm{dd}, J=10.0,2.8 \mathrm{~Hz}, 1 \mathrm{H}), 6.75(\mathrm{dd}, J=10.0$, $2.8 \mathrm{~Hz}, 1 \mathrm{H}), 6.16-6.09(\mathrm{~m}, 2 \mathrm{H}), 4.13-4.07$ (m, 2H), 2.39-2.36 (m, $1 \mathrm{H}), 2.26-2.20(\mathrm{~m}, 1 \mathrm{H}), 2.05-2.00(\mathrm{~m}, 3 \mathrm{H}), 1.92$ (br d, $J=$ $14.0 \mathrm{~Hz}, 1 \mathrm{H}), 1.79$ (br d, $J=12.0,1 \mathrm{H}), 1.52-1.40$ (m, 5H), 1.38$1.20(\mathrm{~m}, 20 \mathrm{H}), 0.88(\mathrm{t}, J=6.8 \mathrm{~Hz}, 3 \mathrm{H}) ;{ }^{13} \mathrm{C} \mathrm{NMR}\left(75 \mathrm{MHz}, \mathrm{CDCl}_{3}\right)$ : 185.3, 150.9, 148.7, 127.3, 127.0, 109.0, 79.7, 65.3, 64.8, 39.1, 39.0, 37.9, 35.8, 34.1, 31.9, 29.6-29.3 (br, 8C), 25.6, 22.6, 14.1; IR (film): 3552, 2925, 2854, 1674, 1632, 1465, 1392, 1220, 1099, 1046, 1000, 853, $772 \mathrm{~cm}^{-1}$; HRMS (ESI): $m / z$ calcd for $\mathrm{C}_{26} \mathrm{H}_{43} \mathrm{O}_{4}{ }^{+}$ $[\mathrm{M}+\mathrm{H}]^{+}:$419.3156, found 419.3156 .

\section{Acknowledgements}

We thank the National Science Foundation of China (21362012, 21062088, 21562020), the Science and Technology Research Projects of the Education Department of Jiangxi Province (No. GJJ14579), the Natural Science Foundation of Jiangxi Province (No. 20151BAB203007), and the Science and Technology Plan Project of Jiangxi Province (No. 20142BBE50006, 20151BBE50004, 20151BBG70028) for the funding support.

\section{Notes and references}

1 World Health Organization, World Malaria Report 2015, World Health Organization, Geneva, Switzerland, 2015, http:/www.who.int/malaria/publications/ world_malaria_report_2014/en/.

2 A. M. Dondorp, F. Nosten, P. Yi, D. Das, A. P. Phyo, J. Tarning, K. M. Lwin, F. Ariey, W. Hanpithakpong, S. J. Lee, P. Ringwald, K. Silamut, M. Imwong, K. Chotivanich, P. Lim, T. Herdman, S. S. An, S. Yeung, P. Singhasivanon, N. P. Day, N. Lindegardh, D. Socheat and N. J. White, N. Engl. J. Med., 2009, 361, 455.

3 (a) J. Heilmann, S. Mayr, R. Brun, T. Rali and O. Sticher, Helv. Chim. Acta, 2000, 83, 2939; (b) J. Heilmann, R. Brun, S. Mayr, T. Rali and O. Sticher, Phytochemistry, 2001, 57, 1281.

4 (a) Y.-S. Wong, Chem. Commun., 2002, 686; (b) J. E. Baldwin, R. M. Adlington, V. W.-W. Sham, R. Márquez and P. G. Bulger, Tetrahedron, 2005, 61, 2353; (c) E. Falomir,
P. Álvarez-Bercedo, M. Carda and J. A. Marco, Tetrahedron Lett., 2005, 46, 8407; (d) P. Álvarez-Bercedo, E. Falomir, M. Carda and J. A. Marco, Tetrahedron, 2006, 62, 9641; (e) M. Peuchmaur and Y.-S. Wong, J. Org. Chem., 2007, 72, 5374; $(f)$ S. Chandrasekhar, Ch. Rambabu and T. Shyamsunder, Tetrahedron Lett., 2007, 48, 4683; $(g)$ C. V. Ramana and B. Srinivas, J. Org. Chem., 2008, 73, 3915; (h) V. Suresh, J. J. P. Selvam, K. Rajesh and Y. Venkateswarlu, Tetrahedron: Asymmetry, 2008, 19, 1509; (i) Z.-B. Zhen, J. Gao and Y. Wu, J. Org. Chem., 2008, 73, 7310; (j) A. Kamal, P. V. Reddy, S. Prabhakar and M. Balakrishna, Tetrahedron: Asymmetry, 2009, 20, 2861; $(k)$ V. Malathong and S. D. Rychnovsky, Org. Lett., 2009, 11, 4220; (l) A. Harbindu and P. Kumar, Synthesis, 2010, 1479; (m) C. V. Ramana and S. K. Pandey, Tetrahedron, 2010, 66, 390; (n) J. S. Yadav, K. V. R. Rao, K. Ravindar and B. V. S. Reddy, Synlett, 2010, 51; (o) J. S. Yadav, N. Thrimurtulu, M. Venkatesh and A. R. Prasad, Synthesis, 2010, 431; (p) J. S. Yadav, Y. G. Rao, D. Chandrakanth, K. Ravindar and B. V. S. Reddy, Helv. Chim. Acta, 2010, 93, 2426; (q) B. Das, M. Krishnaiah and C. Sudhakar, Bioorg. Med. Chem. Lett., 2010, 20, 2303; (r) B. Das, M. Krishnaiah, S. Nagendra and C. R. Reddy, Lett. Org. Chem., 2011, 8, 244; (s) H. B. Yao, L. Y. Song and R. B. Tong, J. Org. Chem., 2014, 73, 1498; $(t)$ S. P. Huang, S. P. Chen, G. P. Wang, J. T. Zhang, L. J. Tang, G. Y. Du and X. J. Wang, Synthesis, 2015, 47, 1303.

5 L. Y. Song, H. L. Yao, Y. J. Dai, M. W. Wu and R. B. Tong, Tetrahedron Lett., 2016, 57, 4257.

6 (a) M. T. Crimmins and J. She, Synlett, 2004, 8, 1371; (b) M. T. Crimmins, B. W. King, E. A. Tabet and K. Chaudhary, J. Org. Chem., 2001, 66, 894.

7 (a) M. T. Crimmins, B. W. King and E. A. Tabet, J. Am. Chem. Soc., 1997, 119, 7883; (b) J. I. Levin, E. Turos and S. M. Weinreb, Synth. Commun., 1982, 12, 989; (c) A. Basha, M. Lipton and S. M. Weinreb, Tetrahedron Lett., 1977, 18, 4171.

8 D. J. Trader and E. E. Carlson, J. Org. Chem., 2013, 78, 7349. 9 T. A. Oster and T. M. Harris, Tetrahedron Lett., 1983, 24, 1851. 10 S. Kawamura, Y. Unno, A. Asai, M. Arisawa and S. Shuto, Org. Biomol. Chem., 2013, 11, 6615.

11 K. Anderson, F. Calo, T. Pfaffeneder, A. J. P. White and A. G. M. Barrett, Org. Lett., 2011, 13, 5748.

12 P. A. Wender, A. V. W. Mayweg and C. L. VanDeusen, Org. Lett. , 2003, 5, 277.

13 H. Wang, B. J. Shuhler and M. Xian, J. Org. Chem., 2007, 72, 4280.

14 D. R. Kelly and S. M. Roberts, Synth. Commun., 1979, 9, 295. 